\title{
The role of adverse childhood experiences as determinants of non-suicidal self-injury among children and adolescents referred to community and inpatient mental health settings
}

\author{
Philip Baiden ${ }^{\mathrm{a}, *}$, Shannon L. Stewart ${ }^{\mathrm{b}}$, Barbara Fallon ${ }^{\mathrm{a}}$ \\ ${ }^{\text {a }}$ Factor-Inwentash Faculty of Social Work, University of Toronto, 246 Bloor Street West, Toronto, ON M5S 1V4, Canada \\ ${ }^{\mathrm{b}}$ Faculty of Education, Western University, 1137 Western Road, London, ON N6G 1G7, Canada
}

\section{A R T I C L E INF O}

\section{Keywords:}

Adverse childhood experiences

Non-suicidal self-injury

Children

Adolescents

interRAI

\begin{abstract}
A B S T R A C T
The objectives of this study were to examine the prevalence of, and determine the effect of adverse childhood experiences on non-suicidal self-injury among children and adolescents referred to community and inpatient mental health settings. Data for this study were obtained from the interRAI Child and Youth Mental Health dataset. A total of 2038 children and adolescents aged 8-18 years $(M=12.49 ; S D=2.88,61.1 \%$ males) were analyzed. Binary logistic regression was fitted to identify predictors of non-suicidal self-injury as a function of adverse childhood experiences, depression, and social support while simultaneously controlling for age, gender, type of patient, legal guardianship, marital status of parents/caregivers, history of foster family placement, and mental health diagnoses. Of the 2038 children and adolescents examined, 592 (29\%) of this clinical sample engaged in non-suicidal self-injury. In the multivariate logistic regression model, children and adolescents who were physically abused had $49 \%$ higher odds of engaging in non-suicidal self-injury and children and adolescents who were sexually abused had $60 \%$ higher odds of engaging in non-suicidal self-injury, when compared to their non-abused counterparts. Other predictors of non-suicidal self-injury include: older age, female gender, inpatient status, depression, attention deficit-hyperactivity disorder, disruptive behavior disorder, and mood disorders. Children and adolescents who had some form of social support had a $26 \%$ decrease in the odds of engaging in non-suicidal self-injury. Assessment procedures for indicators of mental health, particularly among children and adolescents with a history of adverse childhood experiences, should also take into account non-suicidal self-injury. In addition to bolstering social support networks, addressing depression and related emotion regulation skills in childhood may help prevent future non-suicidal self-injury behaviors.
\end{abstract}

\section{Introduction}

The phenomenon of non-suicidal self-injury (NSSI), which is generally defined as "the direct, deliberate destruction of one's own body tissue in the absence of suicidal intent" (Nock \& Favazza, 2009, p. 9), is now recognized globally as a major public health issue, with up to $70 \%$ of children and adolescents with mental health problems engaging in NSSI (Kaess et al., 2013; Thomassin, Shaffer, Madden, \& Londi, 2016; Weismoore \& Esposito-Smythers, 2010; Zetterqvist, Lundh, \& Svedin, 2014). Historically, NSSI has been

\footnotetext{
* Corresponding author.

Email address: philip.baiden@mail.utoronto.ca (P. Baiden)
} 
considered primarily as a symptom of borderline personality disorder (BPD) such that in the third edition of the Diagnostic and Statistical Manual of Mental Disorders (DSM-III) of the American Psychiatric Association (American Psychiatric Association, 1980), it was classified as one of the defining symptoms of BPD and included behaviors such as "physically self-damaging acts, e.g., suicidal gestures, self-mutilation, recurrent accidents or physical fights" (American Psychiatric Association, 1980, p. 323). However, over time, NSSI has begun to be understood more broadly as a behavior requiring its own diagnostic category (Claes \& Vandereycken, 2007; Muehlenkamp, 2005, 2014; Posner, Brodsky, Yershova, Buchanan, \& Mann, 2014). In the DSM-5, NSSI was considered as an autonomous diagnostic category where it was listed in the appendix as one of the mental health conditions requiring further study. The authors of the DSM-5 have proposed the following definition of NSSI "in the last year, the individual has, on 5 or more days, engaged in intentional self-inflicted damage to the surface of his or her body of a sort likely to induce bleeding, bruising, or pain (e.g., cutting, burning, stabbing, hitting, excessive rubbing), with the expectation that the injury will lead to only minor or moderate physical harm" (American Psychiatric Association, 2013, p. 803).

Behaviors such as cutting, pinching, poking, scratching, sticking pins and needles into the skin, and hair pulling, that result in self-injury but with no suicidal intent and causes less lethal damage to bodily tissue are classified as NSSI (Nock \& Favazza, 2009), whereas behaviors, such as self-injury involving fire arms and medication overdose with suicidal intent are classified as suicidal self-injury (SSI) (Messer \& Fremouw, 2008; Muehlenkamp, 2014; Posner et al., 2014). Intent, lethality, and repetition/frequency are three important constructs that distinguish NSSI from SSI. For a detailed discussion of these constructs, the reader is referred to the following papers: Hamza, Stewart, and Willoughby (2012), Silverman, Berman, Sanddal, O'Carroll, and Joiner (2007a) and Silverman, Berman, Sanddal, O'Carroll, and Joiner (2007b).

\subsection{Prevalence estimates of NSSI among children and adolescents}

Prevalence estimates of NSSI among children and adolescents vary widely as a result of a number of factors including the time since last episode of NSSI, number of NSSI episodes to be endorsed, population examined, as well as reasons for engaging in NSSI. Within the Canadian context, prevalence estimates typically range from as low as 7\% in student samples (Duggan, Heath, \& Hu, 2015), to as high as 77\% in clinical samples (Preyde et al., 2014). Using the Deliberate Self-Harm Inventory (DSHI), Heath, Toste, Nedecheva, and Charlebois (2008) assessed NSSI among students from a large urban university in Montreal, Quebec, and found 11.7\% of the students reported engaging in NSSI at some point in their life. In a longitudinal study, Preyde et al. (2012) examined data on 169 children and adolescents from five mental health agencies in southwestern Ontario and found that 57 (34\%) of the participants engaged in NSSI at baseline. Of these 57 participants, 27 (47\%) engaged in mild NSSI behaviors (e.g., repeated pinching), 23 (40\%) engaged in severe NSSI behaviors (e.g., deep razor cuts), and 7 (12\%) engaged in life-threatening NSSI behaviors (e.g., running into the path of an oncoming vehicle on a busy street) (Preyde et al., 2012).

Studies from other jurisdictions have also reported wide variation in prevalence estimates of NSSI among adolescents in clinical samples ranging from 40\% (Kaess et al., 2013) to 80\% (Auerbach et al., 2014). A systematic review performed by Swannell, Martin, Page, Hasking, and St John (2014) to investigate the effect of methodological factors on NSSI in non-clinical samples found a pooled NSSI prevalence estimate among adolescents to be $17.2 \%$. Swannell et al. (2014) also found that methodological factors contributed to more than half of the heterogeneity in prevalence estimates. In addition, Muehlenkamp, Claes, Havertape, and Plener (2012) undertook a systematic review of studies published between 2005 and 2011 on the prevalence rate of NSSI among adolescents and found the mean lifetime prevalence of NSSI across studies to be $18 \%$ (SD $=7.3 \%$ ). They also found that assessing NSSI using a single item often results in a lower prevalence rate than assessment with a specific behavior checklist.

\subsection{Factors associated with NSSI}

One consistent factor that has been identified as a significant predictor of NSSI among adolescents is adverse childhood experiences (ACEs) (Franzke, Wabnitz, \& Catani, 2015; Glassman, Weierich, Hooley, Deliberto, \& Nock, 2007; Gratz, 2006; Kaess et al., 2013; Zetterqvist et al., 2014). Yates (2009) observed that as much as $80 \%$ of those who engaged in NSSI reported having a history of ACEs. ACEs refer to distressing and/or traumatic events that occur during childhood, such as emotional, physical, and sexual abuse; emotional and physical neglect; caregiver risk factors such as of addiction or substance use, mental illness, incarceration, separation or divorce; and violent treatment of the mother(Saul et al., 2014).

Estimates based on data from the Canadian Incidence Study of Reported Child Abuse and Neglect (CIS) suggest that the number of children and adolescents with investigated incidents of child abuse and neglect in Canada is on the rise (Trocmé et al., 2010). For instance, an estimated 135,261 investigated incidents of child abuse and neglect were conducted in Canada in 1998 representing a rate of 21.57 per 1000 children investigations. By 2008, this rate has increased to 39.16 investigations per 1000 children (235,842 child abuse and neglect related investigations) (Trocmé et al., 2010). According to the CIS-2008, more than two-thirds of the substantiated child maltreatment investigations were related to either witnessing domestic violence (34\%) or neglect (34\%), followed by physical abuse (20\%), emotional abuse (9\%), and sexual abuse (3\%).

The extant literature has found a history of ACEs to be associated with increased likelihood of a number of negative outcomes later in life, including anxiety and depression (Coohey, Dirks-Bihun, Renner, \& Baller, 2014; Greger, Myhre, Lydersen, \& Jozefiak, 2015; Larkin, Felitti, \& Anda, 2014), suicide attempt (Dube et al., 2001), alcohol, tobacco, and illicit drug use (Braciszewski \& Colby, 2015; Traube, James, Zhang, \& Landsverk, 2012), poor self-esteem (Arslan, 2016), and risky sexual behavior (Anda et al., 2006; 
Noll, Haralson, Butler, \& Shenk, 2011). Other longitudinal studies (e.g., Lewis et al., 2011), systematic reviews and meta-analyses (Agnew-Blais \& Danese, 2016; Maniglio, 2010, 2012) have also found a strong relationship between ACEs and mental health problems. Using data from the longitudinal study of child abuse and neglect, Lewis et al. (2011) found that history of ACEs predicted internalizing behavior problems at age 14 and cigarette smoking at age 16. Furthermore, Maniglio (2010, 2012) conducted systematic reviews and found that having a history of childhood sexual abuse was a significant risk factor for developing both depression and anxiety disorder, regardless of gender of the victim and severity of the abuse.

With respect to the association between ACEs and NSSI, various systematic reviews and meta-analyses (Ford \& Gómez, 2015; Lang \& Sharma-Patel, 2011; Maniglio, 2011; Smith, Kouros, \& Meuret, 2014) have shown that adolescents with a history of ACEs are more likely to engage in NSSI, even after adjusting for demographic and known mental health factors. Similar results have been found among adolescent inpatients (e.g., Bifulco et al., 2014; Kaess et al., 2013; Thomassin et al., 2016). History of foster placement has also been linked to NSSI (Grenville, Goodman, \& Macpherson, 2012). Shenk, Noll, and Cassarly (2010) examined data on 129 maltreated and 82 non-maltreated adolescent females aged 14-18 years in the Midwest region of the US and found that adolescents who were sexually abused, neglected, or experienced multiple abuses were significantly more likely to report engaging in NSSI. A bourgeoning number of studies have found that children and adolescents exposed to indirect forms of childhood adversities, such as parental addiction or mental health problems or witnessed domestic violence, are at increased risk of engaging in NSSI (Armiento, Hamza, Stewart, \& Leschied, 2016). However, some studies have failed to find a significant association between having a history of ACEs, specifically physical abuse and neglect, and NSSI (Auerbach et al., 2014; Glassman et al., 2007).

Studies that have found a relationship between NSSI and history of ACEs have noted that adolescents with a history of ACEs are likely to have trouble coping with their past traumatic experiences and as a result may engage in NSSI as a means to regulate their affect and emotion, which is referred to as the theory of affect regulation (Messer \& Fremouw, 2008; Suyemoto, 1998). The theory hypothesizes that engaging in NSSI stems from the need to control past experiences of trauma, or anger and pain that cannot be expressed verbally or through other means (Suyemoto, 1998). Various studies, both cross-sectional and longitudinal, have found support for the theory of affect regulation in explaining NSSI among children and adolescents with a history of ACEs (Joiner et al., 2007; Nock \& Prinstein, 2005; Noll, Horowitz, Bonanno, Trickett, \& Putnam, 2003). Brown, Comtois, and Linehan (2002) examined reasons for suicide attempts versus NSSI among 75 suicidal women meeting criteria for BPD and found that the desire to express anger, punish oneself, generate normal feelings, and distract oneself were the most common reasons cited for engaging in NSSI, whereas the desire to make others better off was the most common reason cited for attempting suicide.

Additionally, Nock and Prinstein (2004) examined the functions of NSSI among adolescents and found that more than half (53\%) of their sample engaged in NSSI as a way of regulating their affect (other reasons cited include: to relieve numbness or emptiness, to punish oneself, and to feel relaxed). Bureau et al. (2010) investigated specific aspects underlying the association between early parent-child relationships and NSSI among university students from Eastern Canada. The relationship between the NSSI group and their parents, in comparison to the parent-child relationships in the non-NSSI group, was associated with more failed protection, fear, overprotection, alienation, less care, less trust, and less communication (Bureau et al., 2010). Also, Tatnell, Kelada, Hasking, and Martin (2014) analyzed longitudinal data on 2637 adolescents from 40 high schools across Australia and found that students who grew up in families with insecure attachment had $11 \%$ higher odds of engaging in NSSI at follow-up.

The existing literature has also shown that mental health problems such as anxiety (Claes, Luyckx, Bijttebier et al., 2015), depression (Bentley, Cassiello-Robbins, Vittorio, Sauer-Zavala, \& Barlow, 2015; Tuisku et al., 2006), and alcohol and substance use problems (Brausch \& Boone, 2015; Gratz \& Tull, 2010; Rossow et al., 2007) are significant predictors of NSSI among children and adolescents. Bentley et al. (2015) conducted a meta-analysis on 56 studies that examined NSSI among individuals with and without emotional disorders and found that those diagnosed with emotional disorders, such as mood disorders, anxiety disorders, posttraumatic stress disorder (PTSD), and obsessive-compulsive disorder (OCD), were significantly more likely to report engaging in NSSI than their counterparts with no such diagnosis.

\subsection{Study objective}

Whereas studies from other countries have investigated the effect of ACEs on NSSI among adolescent inpatients (see e.g., Kaess et al., 2013; Thomassin et al., 2016), to date, few studies within the Canadian context have examined the effect of ACEs on NSSI among clinical samples of children and adolescents with mental health problems. Most of the existing studies on NSSI among children and adolescents in Canada are from the general population or relied on student samples where the proportion of individuals with a history of ACEs is much lower than that found in clinical samples or child welfare samples (Heath et al., 2008). Thus, using data from the interRAI Child and Youth Mental Health Assessment, the objectives of this study were to: 1) examine the prevalence of NSSI among children and adolescents referred to community and inpatient mental health settings in Ontario, Canada, and 2) determine the effect of ACEs on NSSI after taking into account demographic factors, depression, social support, and mental health diagnoses. 


\section{Data and methods}

\subsection{Participants}

This study used data from the interRAI Child and Youth Mental Health dataset ChYMH; (Stewart, Hirdes et al., 2015), which was collected from 24 mental health agencies in Ontario from November of 2012 to June 2016. The interRAI ChYMH is a comprehensive instrument comprising of approximately 400 clinical elements covering various behavioral and mental state indicators, stress and trauma, child maltreatment history, strength and resilience, social support, substance use, medication history, DSM-IV diagnostic information, cognitive and executive functioning, health, nutritional status, and a number of scales that can be used for outcome measurement, as well as care planning protocols that can be used to identify areas of imminent concern or risk. Clinicians are trained to complete the instrument using information from various sources including the family, child or youth, other service providers, and clinical records.

The interRAI suite of assessments was designed to be used by researchers and clinicians to assist vulnerable populations and is currently being used internationally. Numerous studies have found items and scales embedded in the ChYMH to have strong psychometric properties (Phillips et al., 2012; Phillips \& Hawes, 2015; Stewart, Currie, Arbeau, Leschied, \& Kerry, 2015; Stewart \& Hamza, 2017). The sample analyzed in this study consisted of 2038 children and adolescents aged $8-18$ years $(M=12.49 ; S D=2.88)$. The majority (61.1\%) of the children and adolescents were males and $239(11.7 \%)$ were inpatients. About 55\% of the children and adolescents lived with both parents, 33.6\% lived with their mother only or their father only, $6.5 \%$ lived alone or lived with other relatives, and the other $5.4 \%$ were from child protection agencies. About $17 \%$ of the children and adolescents had a history of foster family placements. In terms of marital status, $44.1 \%$ of the parents/caregivers were married or lived with a partner, $29.5 \%$ were formerly married, $21.1 \%$ were never married, and 5.4\% were unknown. Of the various mental health diagnoses, $47.4 \%$ had diagnosis of attention-deficit/hyperactivity disorder (ADHD), 38.0\% were diagnosed with anxiety disorders, $24.7 \%$ were diagnosed with disruptive behavior disorders, $23.8 \%$ were diagnosed with learning/communication disorders, $15.1 \%$ were diagnosed with mood disorders, and $11.2 \%$ were diagnosed with autism spectrum disorder. Less than $3.5 \%$ of the children and adolescents had diagnoses of sleep disorders, adjustment disorders, reactive attachment disorder, substance related disorders, eating disorders, and schizophrenia and other psychotic disorders. Ethics approval was sought for analysis of the de-identified data and was approved by the Research Ethics Board of Western University.

\subsection{Measures}

\subsubsection{Outcome variable}

The outcome variable investigated in this study was NSSI; it was assessed using two items that asked for history of self-injurious behavior and the intent behind the self-injurious behavior. Self-injurious behavior was defined as the deliberate and intentional act of self-injury that requires awareness on the part of the child that his or her actions may have a harmful outcome to him or herself. Assessors were asked to evaluate the recency of any self-injurious behavior by the child, including both lethally motivated suicidal behavior and behavior that inflicts self-injury without suicidal intent (e.g., self-cutting, self-mutilation, burning, head-banging, etc.) on a six-point scale ranging from " $0=$ Never", " $1=$ More than a year ago", " $2=31$ days -1 year ago", " $3=8-30$ days ago", " $4=$ $4-7$ days ago", to " $5=$ In the last 3 days". For the purposes of this item, non-intentional, accidental, or unconscious self-destructive behaviors that may lead to injury or premature death are not considered self-injurious behaviors. Those with a history of self-injury were coded as 1 and those with no history of self-injury were coded as 0 . Assessors were also asked to enquire whether the child had ever intentionally engaged in lethally motivated self-injurious behavior with the intent to kill him or herself. This variable was also coded as " $0=$ No" and " $1=$ Yes". For the purposes of this study, those who engaged in self-injurious behavior with the intent to kill themselves were excluded from the analyses since NSSI includes self-injurious behavior with no suicidal intent. A similar method has been used by past studies in measuring NSSI (see e.g., Armiento et al., 2016; Muehlenkamp \& Gutierrez, 2004).

\subsubsection{Explanatory variables}

Explanatory variables examined in this study include a history of emotional abuse, physical abuse, sexual abuse, neglect, witnessing domestic violence, and parental addiction or substance abuse. The recency of occurrence of these stressful and traumatic life events were assessed from child/youth report, teacher report, parent/guardian report, and clinical charts, with the following coding options: " $0=$ Never", " $1=$ more than a year ago", " $2=31$ days to a year ago", " $3=8$ to 30 days ago", " $4=4-7$ days ago", and " 5 = in last 3 days". In the ChYMH assessment manual, emotional abuse refers to placing a child in a pervasively hostile emotional environment created by an abuser for the purpose of control, such that the abused child's self-esteem, identify, energy, ability to feel and question his or her wants and needs are invalidated by the abuser. Physical abuse refers to any incident resulting in non-accidental injury, physical confinement, or excessive physical discipline experienced by the child regardless of his or her age when the incident(s) occurred. Sexual abuse was defined to mean any form of exposure of genitals, sexual touching or coercion, rape experienced by the child regardless of his or her age when the incident(s) occurred. Neglect was defined in reference to failure to provide for basic emotional needs (e.g., primary caregiver not providing sufficient affection, warmth, or sensitivity to the child), physical 
needs (e.g., inadequate winter clothing), or safety needs (e.g., child left in car in summer heat). Witnessing domestic violence refers to the child having an awareness of, or knowledge of, or witnessing physical or verbal actions or threats toward another family member. Parental addiction or substance abuse was defined to mean, parent or primary caregiver having a repetitive and persistent use of alcohol or drugs (Stewart, Hirdes et al., 2015). These variables were coded as binary variables " $0=$ Never" versus " $1=$ Ever."

This study also takes into account social support and measures of depression. Social support was measured based on the availability of support that a child has that he or she can rely on for his or her emotional needs or can draw on in times of crisis. Children who need support but do not have family members (outside the nuclear family) or close friends willing and able to provide consistent support were coded as 0 and compared to their supported counterparts who were coded as 1 .

Lastly, depression was measured as an interval/ratio variable using the interRAI ChYMH Depression Symptoms Scale (DSS) which is a 9-item standardized and validated scale for measuring depression (Stewart \& Hamza, 2017). Assessors were asked to code on a five-point Likert scale (ranging from " $0=$ Not present", " $1=$ present but not exhibited in last 3 days", " $2=$ Exhibited on $1-2$ of last 3 days", "3 = Exhibited daily in the last 3 days, 1-2 episodes", and " 4 = Exhibited daily in last 3 days, 3 or more episodes or continuously") the presence of the following mental state indicators: sad, pained, or worried facial expressions (e.g., furrowed brow, constant frowning); crying, tearfulness; made negative statements (e.g., nothing matters, no one likes me, I hate my life, would rather be dead, what's the use, let me die); self-deprecation (I'm stupid, I'm bad, I can't do anything right, I'm nothing, I'm of no use to anyone); expressions of guilt or shame (e.g., I've done something awful, this is my fault, I'm a terrible person); expressions of hopelessness (there's no hope for the future, nothing is going to change for the better); irritability (marked increase in being short-tempered or easily upset); lack of motivation; and withdrawal from activities of interest (Stewart, Hirdes et al., 2015). Scores on the DSS range from 0 to 36, with higher scores indicating severe symptoms of depression. A receiver operating characteristics (ROC) curve analysis conducted on the DSS yielded the following clinical cut-off values: 0 (none), 1-8 (low), 9-14 (moderate), 15-18 (High), and 19-36 (very high) (Stewart, Fadiya, \& Hirdes, 2016). The DSS has been used among children and adolescents with mental health problems and has been found to have strong psychometric properties (Stewart \& Hamza, 2017). Internal consistency of the 9-items was assessed using Cronbach's alpha to determine the extent to which the items correlate with each other. In the present study, internal consistency (Cronbach's $\alpha$ ) for the DSS was $\alpha=0.81$, suggesting that all the nine items are strongly correlated and measure one construct.

\subsubsection{Control variables}

The study also controlled for the following variables: age, gender, type of patient, legal guardianship, marital status of parents/ caregivers, and history of foster family placement. Age was measured as a continuous variable whereas gender was coded as a binary variable with male as the reference category. Children and adolescents from inpatient mental health clinics were coded as 1 and compared with children and adolescents from outpatient mental health clinics who were coded as 0. Both legal guardianship and marital status of parents/caregivers were measured as nominal variables. Children and adolescents with a history of foster family placement were coded as 1 and compared with their counterparts with no history of foster family placement who were coded as 0 .

\subsection{Data analyses}

Descriptive statistics for all the variables were first conducted using percentages for the categorical variables. Mean, standard deviation, and range were computed for age and depression. The bivariate association between NSSI and the categorical variables was examined using Pearson chi-square test of association and one-way analysis of variance (ANOVA) was used to compare the average age and depression score among children and adolescents who engaged in NSSI versus children and adolescents who did not engage in NSSI. Binary logistic regression was then fitted to identify predictors of NSSI as a function of ACEs, depression, and social support while simultaneously controlling for age, gender, type of patient, legal guardianship, marital status of parents/caregivers, history of foster family placement, and mental health diagnoses. Binary logistic regression was chosen as it is more robust in predicting binary dependent variables with independent variables that could be measured as continuous or categorical variables (Hosmer \& Lemeshow, 2000; Tabachnick \& Fidell, 2007). All the variables were entered in the model using the enter method. A number of model fitness indexes were employed to assess the general fit of the model including the Hosmer-Lemeshow Goodness-Of-Fit test statistic whereby a nonsignificant chi-square test statistic indicates good fit (Hosmer \& Lemeshow, 2000). The Omnibus Tests of Model Coefficients, which follows a chi-square distribution, was also used to evaluate the statistical significance of the logistic regression model. The proportion of variance in NSSI that could be explained by the predictors was assessed based on the Nagelkerke pseudo R square, whereas the proportion of children and adolescents correctly classified as having engaged in NSSI versus having not engaged in NSSI was assessed based on the classification table. Variables were considered significant if the $p$-value was less than 0.05. Adjusted odds ratios (AOR) and 95\% C.I. were reported. All statistical analyses were executed using SPSS Version 23 for Windows (SPSS, Inc., Chicago, IL, USA). 


\section{Results}

\subsection{Sample characteristics}

Table 1 shows the general distribution of the variables examined in this study. Of the 2038 children and adolescents examined, 592 representing 29\% indicated that they had engaged in NSSI. Approximately four out of five children and adolescents (79.1\%) had some family members or close friends who are able to provide consistent support when needed. With respect to ACEs, more than one in four children and adolescents were emotionally abused (26.5\%) or had witnessed domestic violence $(26.6 \%), 19.7 \%$ had parents with addiction or substance abuse issues, $17.6 \%$ had a history of neglect, $16.1 \%$ were physically abused, and $8.1 \%$ were sexually abused. The average depression score among the sample fell within the moderate range $(M=11.13(S D=7.37)$; range $=0-36)$.

\subsection{Bivariate results}

As shown in Table 2, the average age among children and adolescents who engaged in NSSI was significantly greater than the average age among children and adolescents who did not engage in NSSI ( $M_{\text {noNSSI }}=12.01$ versus $M_{\text {NSSI }}=13.66, F(1,2037)=146.82$, $p<0.001)$. Also, the average depression score among children and adolescents who engaged in NSSI was significantly greater than the average depression score among children and adolescents who did not engage in NSSI $\left(M_{\text {noNSSI }}=10.24\right.$ versus $M_{\text {NSSI }}=13.31$, $F(1,2037)=75.55, p<0.001)$.

A number variables examined were significantly associated with NSSI at the bivariate level in Table 3. About $42 \%$ of females compared to $21 \%$ of males engaged in NSSI $\left(\chi^{2}=102.09\right.$, $\left.\mathrm{df}=1, p<0.001\right)$. The proportion of adolescent inpatients that engaged in NSSI $(40.6 \%)$ was significantly greater than the proportion of adolescent outpatients that engaged in NSSI $\left(27.5 \% ; \chi^{2}=17.49\right.$, $\mathrm{df}=1, p<0.001)$. More than one third of adolescents with a history of foster family placement engaged in NSSI (35.4\%) compared to $27.8 \%$ of adolescents with no history of foster family placement that engaged in NSSI $\left(\chi^{2}=7.88, \mathrm{df}=1, p=0.005\right)$. A little over one in three children and adolescents who do not have social support (34.3\%) compared to a little over one in four children and adolescents who have social support (27.6\%) engaged in NSSI $\left(\chi^{2}=7.23\right.$, $\left.\mathrm{df}=1, p<0.001\right)$. Children and adolescents were more likely to engage in NSSI if they: were emotionally abused (39.6\% vs. $25.3 \%, \chi^{2}=39.46$, $\mathrm{df}=1, p<0.001$ ), were physically abused ( $41.9 \%$ vs. $\left.26.6 \%, \chi^{2}=31.66, \mathrm{df}=1, p<0.001\right)$, were sexually abused $\left(53.6 \%\right.$ vs. $26.9 \%, \chi^{2}=52.92, \mathrm{df}=1, p<0.001$ ), were neglected $\left(34.3 \%\right.$ vs. $\left.27.9 \%, \chi^{2}=5.72, \mathrm{df}=1, p=0.017\right)$, witnessed domestic violence $\left(33.9 \%\right.$ vs. $27.3 \%, \chi^{2}=8.6, \mathrm{df}=1$, $p=0.003)$, or had parents with addiction or substance abuse issues $\left(35.6 \%\right.$ vs. $\left.27.4 \%, \chi^{2}=10.34, \mathrm{df}=1, p<0.001\right)$.

Table 4 shows the distribution of ACEs by type of patient (inpatient versus outpatient). The proportion of ACEs among adolescent inpatients was significantly greater than the proportion of ACEs among adolescent outpatients, except sexual abuse which was not statistically significant.

\subsection{Multivariate results}

Although most of the variables were significantly associated with NSSI at the bivariate level, because the bivariate results did not control for the effect of other predictors, we could not ascertain the net effect of each variable on NSSI. The multivariate results adjusted for the effect of all the other predictors. History of foster family placement, legal guardianship, emotional abuse, neglect, witnessing domestic violence, and parental addiction were reduced to nonsignificance once we adjust for other factors in the multivariate model. Results shown in Table 5 indicate that each additional increase in age by 1 year increased the odds of engaging in NSSI by $21 \%$ (AOR $=1.21,95 \%$ C.I. $=1.16-1.27$ ). Odds were more than two times higher for females to engage in NSSI, when compared to their male counterparts $($ AOR $=2.43,95 \%$ C.I. $=1.92-3.06)$. Inpatients had $40 \%$ higher odds of engaging in NSSI when compared with their outpatient counterparts (AOR $=1.40,95 \%$ C.I. $=1.01-1.95$ ). Each additional increase in symptoms of depression increase the odds of engaging in NSSI by $6 \%$, net the effect of all the other predictors (AOR $=1.06$, 95\% C.I. $=1.04-1.07$ ). Children and adolescents with diagnosis of ADHD (AOR $=1.31,95 \%$ C.I. $=1.01-1.69)$, disruptive behavior disorder $($ AOR $=1.52$, 95\% C.I. $=1.15-2.01)$, or mood disorders (AOR $=1.78$, 95\% C.I. $=1.33-2.39)$ also had higher odds of engaging in NSSI. Children and adolescents with a diagnosis of learning or communication disorder had lower odds of engaging in NSSI (AOR = 0.56, 95\% C.I. $=0.43-0.75$ ). Children and adolescents who had some form of social support had a $24 \%$ decrease in the odds of engaging in NSSI when compared to their counterparts who did not have some form of social support (AOR $=0.76,95 \%$ C.I. $=0.58-0.99$ ).

Of the various ACEs variables examined, only physical abuse and sexual abuse emerged as significant predictors of NSSI in the multivariate model. Children and adolescents who were physically abused had 49\% higher odds of engaging in NSSI (AOR = 1.49, $95 \%$ C.I. $=1.06-2.09)$ and children and adolescents who were sexually abused had $60 \%$ higher odds of engaging in NSSI (AOR $=1.60$, 95\% C.I. = 1.09-2.34), when compared to their non-abused counterparts.

Examination of the Hosmer-Lemeshow G.O.F. test statistic indicates that the overall fit of the model was good and, together, the variables made a significant contribution to the model $\left(\chi^{2}=7.37 \mathrm{df}=8, p=0.498\right)$. The Omnibus Tests of Model Coefficients produced a chi-square value of 403.61 , which was statistically significant, $p<0.001$. Together, all the predictors in the model ex- 
Table 1

Sample characteristics $(\mathrm{N}=2038)$.

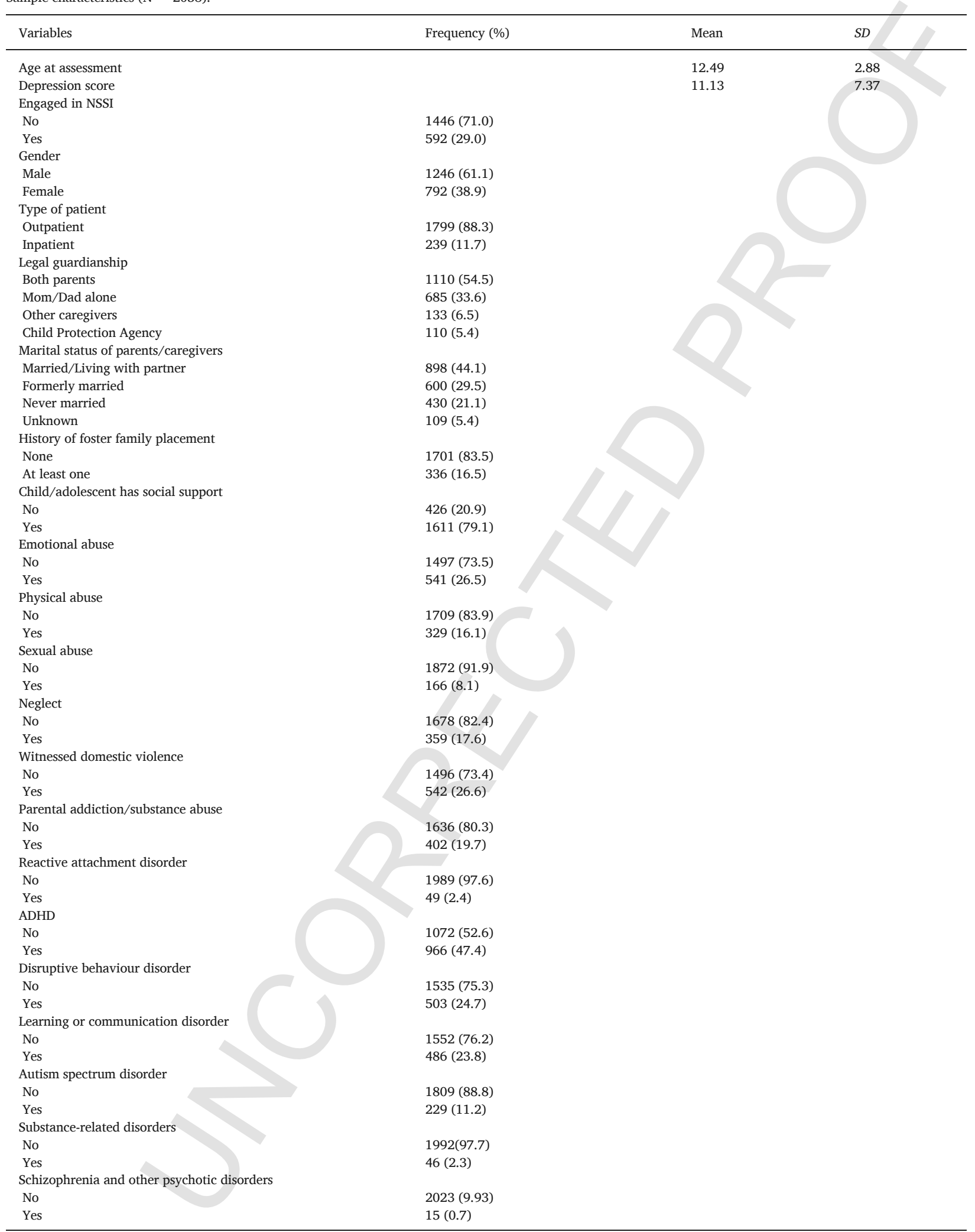


Table 1 (Continued)

\begin{tabular}{|c|c|c|c|}
\hline Variables & & Frequency (\%) & Mean \\
\hline \multicolumn{4}{|l|}{ Mood disorders } \\
\hline No & & 1730 (84.9) & \\
\hline Yes & & $308(15.1)$ & \\
\hline \multicolumn{4}{|l|}{ Anxiety disorders } \\
\hline No & & $1263(62.0)$ & \\
\hline Yes & & $775(38.0)$ & \\
\hline \multicolumn{4}{|l|}{ Eating disorders } \\
\hline No & & 1999 (98.1) & \\
\hline Yes & & $39(1.9)$ & \\
\hline \multicolumn{4}{|l|}{ Sleep disorders } \\
\hline No & & 1974 (96.9) & \\
\hline Yes & & $64(3.1)$ & \\
\hline \multicolumn{4}{|c|}{ Adjustment disorders } \\
\hline No & & 1977 (97.0) & \\
\hline Yes & & $61(3.0)$ & \\
\hline \\
\hline \multicolumn{4}{|c|}{$\begin{array}{l}\text { Table } 2 \\
\text { ANOVA result examining the relationship between NSSI, and age and depression (N = 2038). }\end{array}$} \\
\hline & No NSSI & NSSI & \\
\hline Variables & Mean $(S D)$ & Mean $(S D)$ & $F$ value $(d f)$ \\
\hline Age at assessment & $12.01(2.82)$ & 13.66 (2.69) & $146.82(1,2036)^{\ldots+\ldots * t}$ \\
\hline Depression & $10.24(7.10)$ & $13.31(7.55)$ & $75.55(1,2036)^{* * \hbar}$ \\
\hline
\end{tabular}

${ }^{* * * *} p<0.001$.

plained $25.7 \%$ of the variance in NSSI and $71.6 \%$ of the children were correctly classified as having engaged in NSSI or not engaged in NSSI.

\section{Discussion}

This study sought to examine the prevalence of NSSI among children and adolescents referred to community and inpatient mental health settings in Ontario, Canada, and determine the effect of ACEs on NSSI after controlling for the effect of other known predictors. We found that $29 \%$ of the children and adolescents engaged in NSSI. This proportion is fairly consistent with that found by Preyde et al. (2012) among children and adolescents accessing mental health services in southwestern Ontario but much higher than that found among college students in Canada (e.g., Duggan et al., 2015; Heath et al., 2008). The proportion of adolescents who experienced ACEs and engaged in NSSI may be underestimated and appears to be relatively lower than what has been found in other clinical samples (see e.g., Kaess et al., 2013; Thomassin et al., 2016). The fact that our sample was made up of younger adolescents (mean age $=$ 12.49)could play a role in the proportion of individuals reporting NSSI. In the multivariate logistic regression model, the following factors emerged as predictors of NSSI: older age, female gender, inpatient status, depression, diagnosis of ADHD, disruptive behavior disorder, mood disorders, as well as physical abuse and sexual abuse. Having social support was negatively associated with NSSI.

The finding that older adolescents are more likely to engage in NSSI corroborate past studies that have found NSSI typically begins in adolescence between the ages of 12 and 17 (Claes, Luyckx, Baetens, Van de Ven, \& Witteman, 2015; Muehlenkamp \& Gutierrez, 2004; Sornberger, Heath, Toste, \& McLouth, 2012), although some cases begin after age 18 (Whitlock, Eckenrode, \& Silverman, 2006). Muehlenkamp and Gutierrez (2004) found that by age 13, 15\% of their respondents had engaged in NSSI, 26\% had engaged in NSSI by age 14, and $17 \%$ had engaged in NSSI by age 15. In a longitudinal study, Sourander et al. (2006) examined data on 839 adolescents and 738 parents and found a significant increase in acts of NSSI from age 12 to age 15 . They found that at age $12,2.7 \%$ of adolescent males compared to $3.1 \%$ of adolescent females engaged in NSSI. At age 15, 4.6\% of males compared to $12.6 \%$ of females engaged in NSSI. They also found that compared to children under age 12, adolescents aged 12-15 years old were three times more likely to have engaged in NSSI during the study duration. This finding was maintained even after the researchers had controlled for gender, Child Behavior Checklist (CBCL) internalizing and externalizing behavior scores, nervousness, family structure, and mother's and father's self-perceived health (Sourander et al., 2006).

The finding that adolescent females are more likely to engage in NSSI than their male counterparts both corroborates and contradicts previous research on NSSI. Whereas some scholars (e.g., Christoffersen, Møhl, DePanfilis, \& Vammen, 2015; Heilbron \& Prinstein, 2010; Sornberger et al., 2012; Zetterqvist et al., 2014) have found prevalence rates of NSSI to be higher among adolescent females than their male counterparts, others (e.g., Heath et al., 2008; Hilt, Nock, Lloyd-Richardson, \& Prinstein, 2008; Lloyd-Richardson, Perrine, Dierker, \& Kelley, 2007; Muehlenkamp \& Gutierrez, 2004) failed to find any significant association between gender and NSSI. Sornberger et al. (2012) found that one in three adolescent females compared to one in six adolescent males 
Table 3

Bivariate association between NSSI and predictors $(\mathrm{N}=2038)$.

\begin{tabular}{|c|c|c|c|}
\hline \multirow[t]{2}{*}{ Variables } & \multicolumn{2}{|c|}{ History of NSSI } & \multirow[t]{2}{*}{ Chi-square (sig.) } \\
\hline & No & Yes & \\
\hline Gender & & & $102.09(0.001)$ \\
\hline Male & $985(79.1)$ & $261(20.9)$ & \\
\hline Female & $461(58.2)$ & $331(41.8)$ & \\
\hline Type of patient & & & $17.49(0.001)$ \\
\hline Outpatient & $1305(72.5)$ & 495 (27.5) & \\
\hline Inpatient & $142(59.4)$ & $97(40.6)$ & \\
\hline Legal guardianship & & & $9.77(0.021)$ \\
\hline Both parents & $808(72.8)$ & $302(27.2)$ & \\
\hline Mom/Dad alone & $485(70.8)$ & $200(29.2)$ & \\
\hline Other caregivers & $86(64.7)$ & $47(35.3)$ & \\
\hline Child Protection Agency & $67(60.9)$ & $43(39.1)$ & \\
\hline Marital status of parents/caregivers & & & $5.74(0.125)$ \\
\hline Married/Living with partner & $661(73.4)$ & $237(26.4)$ & \\
\hline Formerly married & $411(68.5)$ & 189 (31.5) & \\
\hline Never married & 299 (69.5) & $131(30.5)$ & \\
\hline Unknown & 74 (67.9) & $35(32.1)$ & \\
\hline History of foster family placement & & & $7.88(0.005)$ \\
\hline None & $1228(72.2)$ & $437(27.8)$ & \\
\hline At least once & $217(64.6)$ & $119(35.4)$ & \\
\hline Social support & & & $7.23(0.007)$ \\
\hline No & $1166(72.4)$ & $445(27.6)$ & \\
\hline Yes & $280(65.7)$ & $146(34.3)$ & \\
\hline Emotional abuse & & & $39.46(0.001)$ \\
\hline No & 1119 (74.7) & $378(25.3)$ & \\
\hline Yes & $327(60.4)$ & $214(39.6)$ & \\
\hline Physical abuse & & & $31.66(0.001)$ \\
\hline No & $1255(73.4)$ & $454(26.6)$ & \\
\hline Yes & $191(58.1)$ & 138 (41.9) & \\
\hline Sexual abuse & & & $52.92(0.001)$ \\
\hline No & $1369(73.1)$ & $503(26.9)$ & \\
\hline Yes & $77(46.4)$ & 89 (53.6) & \\
\hline Neglect & & & $5.72(0.017)$ \\
\hline No & $1209(72.1)$ & 469 (27.9) & \\
\hline Yes & $236(65.7)$ & $123(34.3)$ & \\
\hline Witnessed domestic violence & & & $8.60(0.003)$ \\
\hline No & $1088(72.7)$ & $408(27.3)$ & \\
\hline Yes & $358(66.1)$ & 184 (33.9) & \\
\hline Parental addiction/substance abuse & & & $10.34(0.001)$ \\
\hline No & $1187(72.6)$ & $449(27.4)$ & \\
\hline Yes & $259(64.4)$ & $143(35.6)$ & \\
\hline
\end{tabular}

engaged in NSSI. They also found that among adolescents who reported ever engaging in NSSI, $23 \%$ of females compared to $17.9 \%$ of males engaged in NSSI more frequently.

The manner in which males and females respond to stress (Altemus, 2006; Kuehner, 2003) or regulate emotions (Nolen-Hoeksema, 2012) could be one of the reasons for the gender differences in NSSI prevalence rates. For instance, whereas females are likely to use more internally focused and passive responses such as rumination to regulate emotions, males are more likely to rely on suppression or avoidance such as turning to alcohol to regulate emotions (Nolen-Hoeksema, 2012). As a result, some studies that have found higher NSSI rates among females have also found higher rates of depression among females than males (Andover, Pepper, Ryabchenko, Orrico, \& Gibb, 2005).

We found that although both history of foster family placement and legal guardianship were associated with NSSI at the bivariate level, this effect disappears once we adjust for other factors in the multivariate model. Often, the reason why a child is placed in foster care is due to safety conditions in their family of origin (e.g., abuse, neglect). Once the type of abuse was controlled for in the model, foster placement was no longer significant. This is likely due to the fact that physical and sexual abuse accounted for that effect within our model.

Research has consistently identified the importance of social support and having a confidant as protective factors against NSSI (Claes, Bouman et al., 2015; Christoffersen et al., 2015; Heath, Baxter, Toste, \& McLouth, 2010). Tseng and Yang (2015) found an inverse association between family support and NSSI for both boys and girls as well as between family support and thoughts of NSSI in girls. Andover, Pepper, and Gibb (2007) examined NSSI and coping strategies among 44 adolescents who engaged in NSSI and 44 adolescents as controls and found that those who engaged in NSSI sought support significantly less often from their parents and used avoidance coping strategies more frequently. Having some amount of support provides adolescents with the ability to deliberate on 
Table 4

Bivariate association between type of patient and ACEs $(\mathrm{N}=2038)$.

\begin{tabular}{|c|c|c|c|}
\hline \multirow[t]{2}{*}{ Variables } & \multicolumn{2}{|c|}{ Type of patient } & \multirow[t]{2}{*}{ Chi-square (sig.) } \\
\hline & Outpatient & Inpatient & \\
\hline Emotional abuse & & & $14.66(0.001)$ \\
\hline No & $1346(74.8)$ & $151(63.2)$ & \\
\hline Yes & $453(25.2)$ & $88(36.8)$ & \\
\hline Physical abuse & & & $8.32(0.004)$ \\
\hline No & 1524 (84.7) & $185(77.4)$ & \\
\hline Yes & $275(15.3)$ & $54(22.6)$ & \\
\hline Sexual abuse & & & $1.94(0.164)$ \\
\hline No & $1658(92.2)$ & $214(89.5)$ & \\
\hline Yes & $141(7.8)$ & 25 (10.5) & \\
\hline Neglect & & & $29.60(0.001)$ \\
\hline No & $1512(84.0)$ & $166(69.7)$ & \\
\hline Yes & $287(16.0)$ & $72(30.3)$ & \\
\hline Witnessed domestic violence & & & $18.28(0.000)$ \\
\hline No & $1348(74.9)$ & $148(61.9)$ & \\
\hline Yes & $451(25.1)$ & $91(38.1)$ & \\
\hline Parental addiction/substance abuse & & & $5.75(0.017)$ \\
\hline No & $1458(81.0)$ & $178(74.5)$ & \\
\hline Yes & $341(19.0)$ & $61(25.5)$ & \\
\hline
\end{tabular}

their stressful life situation and avoid taking actions that might be deleterious to their mental health and well-being (Hay \& Meldrum, 2010).

After controlling for demographic factors, depression, and social support, we found that the experience of adversity directed to the child (physical and sexual abuse) predicted NSSI whereas adversities indicative of parental risk such as parental mental health issues and domestic violence were not predictive of NSSI. Although research suggests that direct and indirect abuse often co-occur (Brownridge et al., 2016), our findings corroborates some past studies that have found that only direct abuse toward the child predicts psychopathology (Diamond \& Muller, 2004; McKee \& Payne, 2014). A study by Kulkarni, Graham-Bermann, Rauch, and Seng (2011) also failed to find any significant association between witnessing domestic violence and current and lifetime diagnosis of posttraumatic stress disorder, although direct child abuse was. Additional studies are needed to fully understand the effect of indirect abuse on NSSI.

Sexual abuse has consistently been identified as a risk factor for NSSI (Ford \& Gómez, 2015; Shenk et al., 2010). Bolen, Winter, and Hodges (2013) examined various attachment styles as moderators of the relationship between childhood sexual abuse and NSSI among survivors of childhood sexual abuse entering treatment in the US and found that participants engaged in NSSI as a way to balance their neurophysiological posttraumatic symptoms. Additionally, physical abuse was a significant predictor of NSSI but has not been consistently associated with NSSI in the literature (Auerbach et al., 2014; Glassman et al., 2007). Physical and sexual abuse are two types of abuse that are direct and involve attack on the physical body whereas witnessing domestic violence, emotional abuse, and parental addiction/substance abuse are indirect forms of abuse. It is possible that feelings related to violation of one's body increase the likelihood of engaging in NSSI.

The non-significant findings relating to witnessing domestic violence, neglect, emotional abuse, and parental addiction appears to contradict some past studies (e.g., Bifulco et al., 2014; Kaess et al., 2013; Thomassin et al., 2016). A recent study by Armiento et al. (2016) found exposure to indirect child maltreatment was the only predictor of NSSI after controlling for participants' age and gender. Severity (frequency, intensity, and duration) and recency of direct and indirect abuse may be important to consider in future research to tease apart current findings. Longitudinal research would also be helpful in clarifying the timing of ACEs and age at onset of NSSI.

Depression and mood disorders among adolescents are known predictors of NSSI (Bentley et al., 2015; Duggan et al., 2015; Tuisku et al., 2006), and have also been found in this study. The finding does lend support to the affect regulation theory. Depression is one indication that an individual is having difficulty coping with his/her life situation and being depressed can severely impact one's ability to regulate emotions and focus almost exclusively on the negative aspect of life. Depression can also manifest itself as emotional pain, for which NSSI can be an outlet. Negative statements, feelings of shame/guilt, and expression of sense of hopelessness (e.g., I hate my life, I'm of no use to anyone, I've done something awful, this is my fault, there's no hope for the future, and nothing is going to change for the better) have been observed particularly among survivors of sexual abuse (Aakvaag et al., 2016; Feiring \& Taska, 2005; Gorey, Richter, \& Snider, 2001). The fact that adolescents with ADHD and disruptive behavior disorder are more likely to engage in NSSI is also consistent with other past studies that suggest that adolescents who have difficulty controlling their own behavior or lack planning or insight into their actions may engage in risk-taking behaviors that put the safety of themselves and others at risk (Allely, 2014; Hinshaw et al., 2012; Meza, Owens, \& Hinshaw, 2016).

As a result of this, it is important for clinicians and mental health service professionals to understand that the impact of mental health on life-threatening behaviors, such as NSSI, may be compounded by ACEs, particularly the experience of direct abuse. These 
Table 5

Logistic regression analysis predicting NSSI $(\mathrm{N}=2038)$.

\begin{tabular}{|c|c|c|c|c|}
\hline Variables & $\beta$ & OR & 95\% C.I. & $P$ value \\
\hline Age at assessment & 0.193 & 1.21 & $1.16-1.27$ & 0.001 \\
\hline Gender - Female & 0.886 & 2.43 & $1.92-3.06$ & 0.001 \\
\hline Type of patient - Inpatient & 0.338 & 1.40 & $1.01-1.95$ & 0.045 \\
\hline \multicolumn{5}{|l|}{ Legal guardianship } \\
\hline Both parents (RC) & 1.00 & & & \\
\hline Mom/Dad alone & -0.149 & 0.86 & $0.67-1.10$ & 0.249 \\
\hline Other caregivers & 0.182 & 1.20 & $0.76-1.90$ & 0.435 \\
\hline Child Protection Agency & 0.070 & 1.07 & $0.61-1.90$ & 0.811 \\
\hline \multicolumn{5}{|l|}{ Marital status of parents/caregivers } \\
\hline Married/Living with partner (RC) & 1.00 & & & \\
\hline Formerly married & 0.073 & 1.08 & $0.80-1.45$ & 0.628 \\
\hline Never married & 0.272 & 1.31 & $0.93-1.86$ & 0.123 \\
\hline Unknown & -0.005 & 0.99 & $0.58-1.72$ & 0.986 \\
\hline History of foster family placement & 0.126 & 1.14 & $0.78-1.65$ & 0.509 \\
\hline Depression & 0.056 & 1.06 & $1.04-1.07$ & 0.001 \\
\hline Social support & -0.271 & 0.76 & $0.58-0.99$ & 0.047 \\
\hline Emotional abuse & 0.061 & 1.06 & $0.78-1.45$ & 0.700 \\
\hline Physical abuse & 0.396 & 1.49 & $1.06-2.09$ & 0.023 \\
\hline Sexual abuse & 0.467 & 1.60 & $1.09-2.34$ & 0.017 \\
\hline Neglect & -0.091 & 0.91 & $0.63-1.32$ & 0.626 \\
\hline Witnessed domestic violence & -0.011 & 0.99 & $0.73-1.34$ & 0.943 \\
\hline Parental addiction/substance abuse & 0.211 & 1.24 & $0.91-1.68$ & 0.179 \\
\hline \multicolumn{5}{|l|}{ Provisional psychiatric diagnosis } \\
\hline Reactive attachment disorder & 0.532 & 1.70 & $0.87-3.34$ & 0.122 \\
\hline ADHD & 0.270 & 1.31 & $1.01-1.69$ & 0.040 \\
\hline Disruptive behaviour disorder & 0.421 & 1.52 & $1.15-2.01$ & 0.003 \\
\hline Learning or communication disorder & -0.573 & 0.56 & $0.43-0.75$ & 0.001 \\
\hline Autism spectrum disorder & 0.073 & 1.08 & $0.76-1.53$ & 0.684 \\
\hline Substance-related disorders & 0.657 & 1.93 & $0.98-3.82$ & 0.059 \\
\hline Schizophrenia and other psychotic disorders & 0.855 & 2.35 & $0.74-7.53$ & 0.150 \\
\hline Mood disorders & 0.577 & 1.78 & $1.33-2.39$ & 0.001 \\
\hline Anxiety disorders & -0.035 & 0.97 & $0.77-1.22$ & 0.769 \\
\hline Eating disorders & 0.662 & 1.94 & $0.91-4.13$ & 0.086 \\
\hline Sleep disorders & -0.181 & 0.84 & $0.45-1.56$ & 0.570 \\
\hline Adjustment disorders & 0.202 & 1.22 & $0.67-2.22$ & 0.507 \\
\hline
\end{tabular}

Note: $\mathrm{RC}=$ Reference category.

Hosmer-Lemeshow G.O.F. test statistic $=8.34(0.401)$.

Omnibus chi-square $=403.38$ (0.001).

Nagelkerke pseudo R square $=0.257$.

Overall percent correctly classified $=71.7 \%$.

findings are in line with past studies outside Canada that have investigated the link between ACEs and NSSI among adolescents drawing on clinical samples (Glassman et al., 2007) and non-clinical samples (Gratz, 2006; Zetterqvist et al., 2014). The finding that physical abuse predicts NSSI however, contradicts some past studies that found only sexual abuse and not physical abuse predicted NSSI among their clinical sample of adolescents (Auerbach et al., 2014; Kaess et al., 2013). It is important to note however, that the studies by Auerbach et al. (2014) and Kaess et al. (2013) were hampered by small sample size and lower statistical power (194 and 125 adolescents, respectively).

\subsection{Study limitations}

There are some limitations with this study that should be noted. First, this study relied on cross-sectional data; hence, no causal inferences could be drawn regarding the association between some of the factors associated with NSSI. Additional studies that rely on longitudinal data are needed to tease apart some of the nuances between ACEs and NSSI and some of the inconsistencies in the literature. Second, although the sample was large, and representative of the population of children and adolescents receiving clinical care in Ontario, future studies should examine clinical populations in different geographical regions of Canada. Third, the extant literature on ACEs has acknowledged the importance of measurement in understanding outcomes and specificity. However, the dichotomous nature of the questions examined only whether ACEs occurred or not does not permit for further examination of 'dosage' effects. Future studies that examine the 'dosage' effects of ACEs on NSSI and the underlying mechanism through which risk and protective factors influence NSSI may assist in the identification of children and adolescents with a history of ACEs who are more or less likely to engage in NSSI. Additional studies are also needed to ascertain how generalizable the findings of the present study would 
be to other mental health settings outside Canada. Lastly, cross-cultural studies using the ChYMH would provide additional evidence of the impact of ACEs on NSSI.

\subsection{Clinical implications}

The findings of this study have implications for child and adolescent mental health delivery in Ontario. Children and adolescents who experienced physical and sexual abuse are at higher risk of engaging in NSSI. Assessment procedures that incorporate indicators of mental health issues particularly among children and adolescents with a history of ACEs should also take into account NSSI. Children and adolescents with a history of ACEs and depression are at an even greater risk of engaging in NSSI. From a clinical perspective, understanding the mechanism through which NSSI may occur can inform clinicians and social workers working with formerly abused children and adolescents in preventing future NSSI behaviors. A combination of ACEs and symptoms of depression among children and adolescents who engage in NSSI can also alert clinicians to develop interventions aimed at helping these individuals and their caregivers with emotion regulation skills so as to cope with past trauma and consequently enhance their mental health well-being. Teaching emotion regulation skills in childhood for those who have experienced physical or sexual abuse may also help prevent future NSSI behaviors. Social support is a protective factor and adds to the literature that advocates for a focus on resilience and increasing support as a way to improve functioning. Interventions targeting children and adolescents with a history of ACEs should also consider ways to help them establish early in life a close tie with at least one family member or peer who will be sensitive to their emotions and also take their needs into account.

\section{Uncited reference}

Allely (2014).

\section{Acknowledgements}

This research was supported in part by Joseph-Armand Bombardier Canada Graduate Scholarship-Doctoral Award through Social Sciences and Humanities Research Council (SSHRC) of Canada awarded to the first author. This research was also supported by the Community Vitality Grant through the London Community Foundation. Special thanks to the children, youth, and families for their time and effort.

\section{References}

Aakvaag, H.F., Thoresen, S., Wentzel-Larsen, T., Dyb, G., Røysamb, E., Olff, M., 2016, 16-23. Broken and guilty since it happened: A population study of trauma-related shame and guilt after violence and sexual abuse. Journal of Affective Disorders 204,

Agnew-Blais, J., Danese, A., 2016. Childhood maltreatment and unfavourable clinical outcomes in bipolar disorder: A systematic review and meta-analysis. The Lancet Psychiatry 3 (4), 342-349.

Allely, C.S., 2014. The association of ADHD symptoms to self-harm behaviours: a systematic PRISMA review. BMC Psychiatry 14 (1), 2-13. http://dx.doi.org/10.1186/ 1471-244X-14-133.

Altemus, M., 2006. Sex differences in depression and anxiety disorders: Potential biological determinants. Hormones and Behavior 50 (4), 534-538.

American Psychiatric Association, 1980. Diagnostic and statistical manual of mental disorders-III. American Psychiatric Association, Washington, DC.

American Psychiatric Association, 2013. Diagnostic and statistical manual of mental disorders: DSM-V, 5th ed. American Psychiatric Association, Washington, DC.

Anda, R.F., Felitti, V.J., Bremner, J.D., Walker, J.D., Whitfield, C.H., Perry, B.D., ... Giles, W.H., 2006. The enduring effects of abuse and related adverse experiences in childhood. European Archives of Psychiatry and Clinical Neuroscience 256 (3), 174-186.

Andover, M.S., Pepper, C.M., Ryabchenko, K.A., Orrico, E.G., Gibb, B.E., 2005. Self-Mutilation and symptoms of depression, anxiety, and borderline personality disorder. Suicide and Life-Threatening Behavior 35 (5), 581-591.

Andover, M.S., Pepper, C.M., Gibb, B.E., 2007. Self-mutilation and coping strategies in a college sample. Suicide and Life-Threatening Behavior 37 (2), $238-243$.

Armiento, J., Hamza, C.A., Stewart, S.L., Leschied, A., 2016. Direct and indirect forms of childhood maltreatment and nonsuicidal self-injury among clinically-referred children and youth. Journal of Affective Disorders 200, 212-217.

Arslan, G., 2016. Psychological maltreatment, emotional and behavioral problems in adolescents: The mediating role of resilience and self-esteem. Child Abuse \& Neglect 52, 200-209.

Auerbach, R.P., Kim, J.C., Chango, J.M., Spiro, W.J., Cha, C., Gold, J., ... Nock, M.K., 2014. Adolescent nonsuicidal self-injury: Examining the role of child abuse, comorbidity, and disinhibition. Psychiatry Research 220 (1-2), 579-584.

Bentley, K.H., Cassiello-Robbins, C.F., Vittorio, L., Sauer-Zavala, S., Barlow, D.H., 2015. The association between nonsuicidal self-injury and the emotional disorders: A meta-analytic review. Clinical Psychology Review 37, 72-88.

Bifulco, A., Schimmenti, A., Moran, P., Jacobs, C., Bunn, A., Rusu, A.C., 2014. Problem parental care and teenage deliberate self-harm in young community adults. Bulletin of the Menninger Clinic 78 (2), 95-114.

Bolen, R.M., Winter, V.R., Hodges, L., 2013. Affect and state dysregulation as moderators of the relationship between childhood sexual abuse and nonsuicidal self-injury. Journal of Interpersonal Violence 28 (1), 201-228.

Braciszewski, J.M., Colby, S.M., 2015. Tobacco use among foster youth: Evidence of health disparities. Children and Youth Services Review 58, $142-145$.

Brausch, A.M., Boone, S.D., 2015. Frequency of nonsuicidal Self-Injury in adolescents: Differences in suicide attempts, substance use, and disordered eating. Suicide and Life-Threatening Behavior 45 (5), 412-622.

Brown, M.Z., Comtois, K.A., Linehan, M.M., 2002. Reasons for suicide attempts and nonsuicidal self-injury in women with borderline personality disorder. Journal of Abnormal Psychology 111 (1), 198-202.

Brownridge, D.A., Taillieu, T., Afifi, T., Chan, K.L., Emery, C., Lavoie, J., Elgar, F., 2016. Child maltreatment and intimate partner violence among indigenous and non-indigenous Canadians. Journal of Family Violence 1-13.

Bureau, J., Martin, J., Freynet, N., Poirier, A.A., Lafontaine, M., Cloutier, P., 2010. Perceived dimensions of parenting and non-suicidal self-injury in young adults. Journal of Youth and Adolescence 39 (5), 484-494.

Christoffersen, M.N., Møhl, B., DePanfilis, D., Vammen, K.S., 2015. Non-suicidal self-Injury—Does social support make a difference? An epidemiological investigation of a Danish national sample. Child Abuse \& Neglect 44, 106-116. 
Claes, L., Vandereycken, W., 2007. Self-injurious behavior: Differential diagnosis and functional differentiation. Comprehensive Psychiatry 48 (2), 137-144.

Claes, L., Bouman, W.P., Witcomb, G., Thurston, M., Fernandez-Aranda, F., Arcelus, J., 2015. Non-suicidal self-injury in trans people: Associations with psychological symptoms, victimization, interpersonal functioning, and perceived social support. The Journal of Sexual Medicine 12 (1), $168-179$.

Claes, L., Luyckx, K., Baetens, I., Van de Ven, M., Witteman, C., 2015. Bullying and victimization, depressive mood, and non-suicidal self-injury in adolescents: The moderating role of parental support. Journal of Child and Family Studies 24 (11), 3363-3371.

Claes, L., Luyckx, K., Bijttebier, P., Turner, B., Ghandi, A., Smets, J., ... Goris, Y., 2015. Non-suicidal self-injury in patients with eating disorder: Associations with identity formation above and beyond anxiety and depression. European Eating Disorders Review 23 (2), 119-125.

Coohey, C., Dirks-Bihun, A., Renner, L.M., Baller, R., 2014. Strain, depressed mood and suicidal thoughts among maltreated adolescents in the united states. Child Abuse \& Neglect 38 (7), 1171-1179.

Diamond, T., Muller, R.T., 2004. The relationship between witnessing parental conflict during childhood and later psychological adjustment among university students: Disentangling confounding risk factors. Canadian Journal of Behavioural Science 36 (4), 295-309.

Dube, S.R., Anda, R.F., Felitti, V.J., Chapman, D.P., Williamson, D.F., Giles, W.H., 2001. Childhood abuse, household dysfunction, and the risk of attempted suicide throughout the life span: Findings from the Adverse Childhood Experiences Study. JAMA 286 (24), 3089-3096.

Duggan, J., Heath, N., Hu, T., 2015. Non-suicidal self-injury maintenance and cessation among adolescents: A one-year longitudinal investigation of the role of objectified body consciousness, depression and emotion dysregulation. Child and Adolescent Psychiatry and Mental Health 9 (1), 1-12.

Feiring, C., Taska, L.S., 2005. The persistence of shame following sexual abuse: A longitudinal look at risk and recovery. Child Maltreatment 10 (4), 337-349.

Ford, J.D., Gómez, J.M., 2015. The relationship of psychological trauma and dissociative and posttraumatic stress disorders to nonsuicidal self-injury and suicidality: A review. Journal of Trauma \& Dissociation 16 (3), 232-271.

Franzke, I., Wabnitz, P., Catani, C., 2015. Dissociation as a mediator of the relationship between childhood trauma and nonsuicidal self-injury in females: A path analytic approach. Journal of Trauma \& Dissociation 16 (3), 286-302.

Glassman, L.H., Weierich, M.R., Hooley, J.M., Deliberto, T.L., Nock, M.K., 2007. Child maltreatment, non-suicidal self-injury, and the mediating role of self-criticism. Behaviour Research and Therapy 45 (10), 2483-2490.

Gorey, K.M., Richter, N.L., Snider, E., 2001. Guilt, isolation and hopelessness among female survivors of childhood sexual abuse: Effectiveness of group work intervention. Child Abuse \& Neglect 25 (3), 347-355.

Gratz, K.L., Tull, M.T., 2010. The relationship between emotion dysregulation and deliberate self-harm among inpatients with substance use disorders. Cognitive Therapy and Research 34 (6), 544-553.

Gratz, K.L., 2006. Risk factors for deliberate self-harm among female college students: The role and interaction of childhood maltreatment, emotional inexpressivity, and affect intensity/reactivity. American Journal of Orthopsychiatry 76 (2), 238.

Greger, H.K., Myhre, A.K., Lydersen, S., Jozefiak, T., 2015. Previous maltreatment and present mental health in a high-risk adolescent population. Child Abuse \& Neglect 45, 122-134.

Grenville, J., Goodman, D., Macpherson, A.K., 2012. Characteristics of self-harm behaviour among identified self-harming youth in care. International Journal of Mental Health and Addiction 10 (5), 646-659.

Hamza, C.A., Stewart, S.L., Willoughby, T., 2012. Examining the link between nonsuicidal self-injury and suicidal behavior: A review of the literature and an integrated model. Clinical Psychology Review 32, 482-495.

Hay, C., Meldrum, R., 2010. Bullying victimization and adolescent self-harm: Testing hypotheses from general strain theory. Journal of Youth and Adolescence 39 (5), $446-459$.

Heath

et al.,

2008. N.L. Heath, J.R. Toste, T. Nedecheva, A. Charlebois, An examination of nonsuicidal self-injury among college students, Journal of Mental Health Counseling 30 (2) (2008) 137-156.

Heath, N.L., Baxter, A.L., Toste, J.R., McLouth, R., 2010. Adolescents' willingness to access school-based support for nonsuicidal self-injury. Canadian Journal of School Psychology 25 (3), 260-276.

Hilt, L.M., Nock, M.K., Lloyd-Richardson, E.E., Prinstein, M.J., 2008. Longitudinal study of nonsuicidal self-injury among young adolescents rates, correlates, and preliminary test of an interpersonal model. The Journal of Early Adolescence 28 (3), 455-469.

Hinshaw, S.P., Owens, E.B., Zalecki, C., Huggins, S.P., Montenegro-Nevado, A.J., Schrodek, E., Swanson, E.N., 2012. Prospective follow-up of girls with attention-deficit/hyperactivity disorder into early adulthood: Continuing impairment includes elevated risk for suicide attempts and self-injury. Journal of Consulting and Clinical Psychology 80 (6), 1041-1051.

Hosmer, D.W., Lemeshow, S., 2000. Applied logistic regression, 2nd ed. Wiley, New York.

Joiner, T.E., Sachs-Ericsson, N.J., Wingate, L.R., Brown, J.S., Anestis, M.D., Selby, E.A., 2007. Childhood physical and sexual abuse and lifetime number of suicide attempts: A persistent and theoretically important relationship. Behaviour Research and Therapy 45 (3), 539-547.

Kaess, M., Parzer, P., Mattern, M., Plener, P.L., Bifulco, A., Resch, F., Brunner, R., 2013. Adverse childhood experiences and their impact on frequency, severity, and the individual function of nonsuicidal self-injury in youth. Psychiatry Research 206 (2), 265-272.

Kuehner, C., 2003. Gender differences in unipolar depression: An update of epidemiological findings and possible explanations. Acta Psychiatrica Scandinavica 108 (3), $163-174$.

Kulkarni, M.R., Graham-Bermann, S., Rauch, S.A., Seng, J., 2011. Witnessing versus experiencing direct violence in childhood as correlates of adulthood PTSD. Journal of Interpersonal Violence 26 (6), 1264-1281.

Lang, C.M., Sharma-Patel, K., 2011. The relation between childhood maltreatment and self-injury: A review of the literature on conceptualization and intervention. Trauma, Violence \& Abuse 12 (1), 23-37.

Larkin, H., Felitti, V.J., Anda, R.F., 2014. Social work and adverse childhood experiences research: Implications for practice and health policy. Social Work in Public Health 29 (1), 1-16.

Lewis, T.L., Kotch, J., Wiley, T.R., Litrownik, A.J., English, D.J., Thompson, R., ... Dubowitz, , 2011. Internalizing problems: A potential pathway from childhood maltreatment to adolescent smoking. Journal of Adolescent Health 48 (3), 247-252.

Lloyd-Richardson, E.E., Perrine, N., Dierker, L., Kelley, M.L., 2007. Characteristics and functions of non-suicidal self-injury in a community sample of adolescents. Psychological Medicine 37 (08), 1183-1192.

Maniglio, R., 2010. Child sexual abuse in the etiology of depression: A systematic review of reviews. Depression and Anxiety 27 (7), 631-642.

Maniglio, R., 2011. The role of child sexual abuse in the etiology of suicide and non-suicidal self-injury. Acta Psychiatrica Scandinavica 124 (1), 30-41.

Maniglio, R., 2012. Child sexual abuse in the etiology of anxiety disorders: A systematic review of reviews. Trauma, Violence \& Abuse 14 (2), $96-112$.

McKee, J.R., Payne, B.K., 2014. Witnessing domestic violence as a child and adulthood emotionality: Do adults feel the consequences of exposure to partner abuse later in the life course?. Journal of Aggression, Maltreatment \& Trauma 23 (3), 318-331.

Messer, J.M., Fremouw, W.J., 2008. A critical review of explanatory models for self-mutilating behaviors in adolescents. Clinical Psychology Review 28 (1), 162-178.

Meza, J.I., Owens, E.B., Hinshaw, S.P., 2016. Response inhibition, peer preference and victimization, and self-harm: Longitudinal associations in young adult women with and without ADHD. Journal of Abnormal Child Psychology 44 (2), 323-334.

Muehlenkamp, J.J., Gutierrez, P.M., 2004. An investigation of differences between Self-Injurious behavior and suicide attempts in a sample of adolescents. Suicide and Life-Threatening Behavior 34 (1), 12-23.

Muehlenkamp, J.J., Claes, L., Havertape, L., Plener, P.L., 2012. International prevalence of adolescent non-suicidal self-injury and deliberate self-harm. Child and Adolescent Psychiatry and Mental Health 6 (10), 1-9.

Muehlenkamp, J.J., 2005. Self-injurious behavior as a separate clinical syndrome. American Journal of Orthopsychiatry 75 (2), $324-333$.

Muehlenkamp, J.J., 2014. Distinguishing between suicidal and nonsuicidal self-injury. In: Nock, M.K. (Ed.), The oxford handbook of suicide and self-injury. Oxford University Press, New York, NY, pp. 23-46. 
Nock, M.K., Favazza, A.R., 2009. Nonsuicidal self-injury: Definition and classification. In: Nock, M.K. (Ed.), Understanding nonsuicidal self-injury: Origins, assessment, and treatment. American Psychological Association, Washington, DC, pp. 9-18.

Nock, M.K., Prinstein, M.J., 2004. A functional approach to the assessment of self-mutilative behavior. Journal of Consulting and Clinical Psychology 72 (5), 885-890.

Nock, M.K., Prinstein, M.J., 2005. Contextual features and behavioral functions of self-mutilation among adolescents. Journal of Abnormal Psychology 114 (1), 140-146.

Nolen-Hoeksema, S., 2012. Emotion regulation and psychopathology: The role of gender. Annual Review of Clinical Psychology 8, $161-187$.

Noll, J.G., Horowitz, L.A., Bonanno, G.A., Trickett, P.K., Putnam, F.W., 2003. Revictimization and self-harm in females who experienced childhood sexual abuse: Results from a prospective study. Journal of Interpersonal Violence 18 (12), 1452-1471.

Noll, J.G., Haralson, K.J., Butler, E.M., Shenk, C.E., 2011. Childhood maltreatment, psychological dysregulation, and risky sexual behaviors in female adolescents. Journal of Pediatric Psychology 36 (7), 743-752.

Phillips, C.D., Hawes, C., 2015. The interRAI pediatric home care (PEDS HC) assessment: Evaluating the long-term community-based service and support needs of children facing special healthcare challenges. Health Services Insights 8, 17-24.

Phillips, C.D., Patnaik, A., Moudouni, D.K., Naiser, E., Dyer, J.A., Hawes, C., ... Elliott, T.R., 2012. Summarizing activity limitations in children with chronic illnesses living in the community: A measurement study of scales using supplemented interRAI items. BMC Health Services Research $12,19$.

Posner, K., Brodsky, B., Yershova, K., Buchanan, J., Mann, J., 2014. The classification of suicidal behavior. In: Nock, M.K. (Ed.), The oxford handbook of suicide and self-injury. Oxford University Press, New York, NY, pp. 7-22.

Preyde, M., Watkins, H., Csuzdi, N., Carter, J., Lazure, K., White, S., ... Frensch, , 2012. Non-suicidal self-injury and suicidal behaviour in children and adolescents accessing residential or intensive home-based mental health services. Journal of the Canadian Academy of Child and Adolescent Psychiatry 21 (4), $270-281$.

Preyde, M., Vanderkooy, J., Chevalier, P., Heintzman, J., Warne, A., Barrick, K., 2014. The psychosocial characteristics associated with NSSI and suicide attempt of youth admitted to an in-patient psychiatric unit. Journal of the Canadian Academy of Child and Adolescent Psychiatry 23 (2), $100-110$.

Rossow, I., Ystgaard, M., Hawton, K., Madge, N., Van Heeringen, K., De Wilde, E.J., ... Morey, , 2007. Cross-National comparisons of the association between alcohol consumption and deliberate Self-Harm in adolescents. Suicide and Life-Threatening Behavior 37 (6), $605-615$.

Saul, J., Valle, L.A., Mercy, J.A., Turner, S., Kaufmann, R., Popovic, T., Centers for Disease Control Prevention (CDC), 2014. CDC grand rounds: Creating a healthier future through prevention of child maltreatment. MMWR. Morbidity and Mortality Weekly Report 63 (12), 260-263. mm6312a2 [pii].

Shenk, C.E., Noll, J.G., Cassarly, J.A., 2010. A multiple mediational test of the relationship between childhood maltreatment and non-suicidal self-injury. Journal of Youth and Adolescence 39 (4), 335-342.

Silverman, M.M., Berman, A.L., Sanddal, N.D., O'Carroll, P.W., Joiner, T.E., 2007. Rebuilding the tower of babel: A revised nomenclature for the study of suicide and suicidal behaviors part 1: Background, rationale, and methodology. Suicide and Life-Threatening Behavior 37 (3), $248-263$.

Silverman, M.M., Berman, A.L., Sanddal, N.D., O'Carroll, P.W., Joiner, T.E., 2007. Rebuilding the tower of babel: A revised nomenclature for the study of suicide and suicidal behaviors part 2: Suicide-related ideations, communications, and behaviors. Suicide and Life-Threatening Behavior 37 (3), $264-277$.

Smith, N.B., Kouros, C.D., Meuret, A.E., 2014. The role of trauma symptoms in nonsuicidal self-injury. Trauma, Violence, and Abuse: A Review Journal 15 (1), $41-56$.

Sornberger, M.J., Heath, N.L., Toste, J.R., McLouth, R., 2012. Nonsuicidal self-injury and gender: Patterns of prevalence, methods, and locations among adolescents. Suicide and Life-Threatening Behavior 42 (3), 266-278.

Sourander, A., Aromaa, M., Pihlakoski, L., Haavisto, A., Rautava, P., Helenius, H., Sillanpää, M., 2006. Early predictors of deliberate self-harm among adolescents. A prospective follow-up study from age 3 to age 15. Journal of Affective Disorders 93 (1), 87-96.

Stewart, S.L., Hamza, C.A., 2017. The Child and Youth Mental Health Assessment (ChYMH): An examination of the psychometric properties of an integrated assessment developed for clinically referred children and youth. BMC Health Services Research 17 (82), 1-10. http://dx.doi.org/10.1186/s12913-016-1970-9.

Stewart, S.L., Currie, M., Arbeau, K., Leschied, A., Kerry, A., 2015. Assessment and planning for community and custodial services: The application of interRAI assessment in the youth justice system. Serious and violent young offenders and youth criminal justice: A Canadian perspective, Simon Fraser University Press, Burnaby, BC.

Stewart, S.L., Hirdes, J., Curtin-Telegdi, N., Perlman, C., McKnight, M., MacLeod, K., ... Morris, , 2015. interRAI child and youth mental health (ChYMH) assessment form and user's manual: For use with in-patient and community-based assessments.

Stewart, S.L., Fadiya, B., Hirdes, J.P., 2016. Cut points for selected scales of the interRAI Child and Youth Mental Health instrument. In: Paper presented at the InterRAI Network of Excellence in Mental Health, Capetown, South Africa. November 2016.

Suyemoto, K.L., 1998. The functions of self-mutilation. Clinical Psychology Review 18 (5), 531-554.

Swannell, S.V., Martin, G.E., Page, A., Hasking, P., St John, N.J., 2014. Prevalence of nonsuicidal Self-Injury in nonclinical samples: Systematic review, meta-analysis and meta-regression. Suicide and Life-Threatening Behavior 44 (3), 273-303.

Tabachnick, B.G., Fidell, L.S., 2007. In: Fidell, L.S. (Ed.), Using multivariate statistics, 5th ed. Pearson/Allyn \& Bacon, Boston.

Tatnell, R., Kelada, L., Hasking, P., Martin, G., 2014. Longitudinal analysis of adolescent NSSI: The role of intrapersonal and interpersonal factors. Journal of Abnormal Child Psychology 42 (6), 885-896.

Thomassin, K., Shaffer, A., Madden, A., Londino, D.L., 2016. Specificity of childhood maltreatment and emotion deficit in nonsuicidal self-injury in an inpatient sample of youth. Psychiatry Research 244, 103-108.

Traube, D.E., James, S., Zhang, J., Landsverk, J., 2012. A national study of risk and protective factors for substance use among youth in the child welfare system. Addictive Behaviors 37 (5), 641-650.

Trocmé, N., Fallon, B., MacLaurin, B., Daciuk, J., Felstiner, C., Black, T., 2010. Canadian incidence study of reported child abuse and neglect-2003. Public Health Agency of Canada Ottawa.

Tseng, F., Yang, H., 2015. Internet use and web communication networks, sources of social support, and forms of suicidal and nonsuicidal Self-Injury among adolescents: Different patterns between genders. Suicide and Life-Threatening Behavior 45 (2), 178-191.

Tuisku, V., Pelkonen, M., Karlsson, L., Kiviruusu, O., Holi, M., Ruuttu, T., ... Marttunen, M., 2006. Suicidal ideation, deliberate self-harm behaviour and suicide attempts among adolescent outpatients with depressive mood disorders and comorbid axis I disorders. European Child \& Adolescent Psychiatry 15 (4), 199-206.

Weismoore, J.T., Esposito-Smythers, C., 2010. The role of cognitive distortion in the relationship between abuse, assault, and non-suicidal self-injury. Journal of Youth and Adolescence 39 (3), 281-290.

Whitlock, J., Eckenrode, J., Silverman, D., 2006. Self-injurious behaviors in a college population. Pediatrics 117 (6), 1939-1948. http://dx.doi.org/10.1542/peds. 2005-2543.

Yates, T.M., 2009. Developmental pathways from child maltreatment to nonsuicidal self-injury.

Zetterqvist, M., Lundh, L., Svedin, C.G., 2014. A cross-sectional study of adolescent non-suicidal self-injury: Support for a specific distress-function relationship. Child and Adolescent Psychiatry and Mental Health 8 (23), 1-14. 